\title{
Blood cells as functional markers of antioxidant vitamin status
}

\author{
Josep Tur-Marí*, Antoni Sureda and Antoni Pons \\ Laboratory of Physical Activity Sciences, Community Nutrition and Oxidative Stress Research Group (IUNICS), University of the \\ Balearic Islands, Guillem Colom Building, Campus, E-07122 Palma de Mallorca, Spain
}

\begin{abstract}
Antioxidants have shown beneficial effects in several biological systems, in which they were able to prevent oxidative stress-associated damage. Vitamins C and E are key antioxidants in man. Dietary intake cannot accurately reflect plasma vitamin levels. However, the plasma levels of antioxidant vitamins could also reflect the acute assimilation of these vitamins. It has been pointed out that antioxidant vitamin blood contents reach a saturation level by intake of dietary supplements. Antioxidant vitamin plasma levels are the parameter most used to determine antioxidant status. However, the vitamin plasma levels may not reflect the nutritional status of vitamins. It has been pointed out that the vitamin $\mathrm{E}$ in adipose tissue can be used as a measure of vitamin E status. To determinate antioxidant vitamin contents in lymphocytes and neutrophils after exercise is a useful tool to assess the functional status of antioxidant vitamins.
\end{abstract}

Antioxidants: Vitamin E: Vitamin C: Oxidative stress: Exhaustive exercise

Oxidative stress is believed to be an important causative factor in human ageing and in the development of chronic disease, operating through the formation and effect of oxidatively damaged macromolecules or their degradation products. Several pathophysiological mechanisms are known to cause an overproduction of reactive oxygen species (ROS), including exposure to transition metal ions and activation of polymorphonuclear neutrophils and macrophages, leading to the generation of superoxide anions and hypochlorite ( $\mathrm{Ji}, 1999)$.

Many antioxidants have shown beneficial effects in different biological systems, in which they were able to prevent oxidative stress-associated damage. Epidemiological evidence indicates that high plasma concentrations of exogenous antioxidants are associated with lower risk of CVD and several types of cancer (Morrisey \& Sheehy, 1999; Padayatty et al. 2003). This important function of antioxidant vitamins means that adequate indicators of the situation of antioxidant vitamins depots and availability must be found.

A varied and balanced diet should provide adequate amounts of all nutrients. Vitamins $\mathrm{C}$ and $\mathrm{E}$ are key antioxidants which in man are exclusively obtained from the diet. Vitamin $\mathrm{C}$ is hydrophilic and protects water-soluble components of the body, while vitamin $\mathrm{E}$ is a lipid-soluble antioxidant which protects cell membranes from peroxidative damage. There is evidence that these key antioxidants may interact in vivo. Vitamin $\mathrm{C}$ in the aqueous phase is capable of recycling lipid-bound vitamin E. Antioxidant vitamin status depends not only on vitamin intake, but can also be influenced by other factors such as exercise, smoking habits and levels of other nutrients in the diet which may influence the absorption and metabolism of antioxidant vitamins (Hamilton et al. 2000; Traber et al. 2001; Aguiló et al.
2003). Therefore, dietary intake cannot accurately reflect plasma vitamins levels. However, the plasma levels of antioxidant vitamins could also reflect the acute assimilation of these vitamins.

\section{Functional foods to increase the bioavailability of antioxidant vitamins}

In the scientific arena, there is some controversy about how much antioxidant vitamins are required to avoid suboptimal supply and deficiency (Food and Nutrition Board, 2000; Horwitt, 2001; Traber, 2001), or to avoid oxidative damage in people engaged in physical activity (Packer \& Obermüller-Jevic, 2002). Conflicting results from vitamin $E$ intervention studies suggest supplemental vitamin E malabsorption, but also that the bioavailability of vitamin $\mathrm{E}$ increases with a rich-fat meal (Leonard et al. 2004) and the absorption of vitamin E depends on an individual's ability to absorb fat; thus to obtain maximal absorption, vitamin $\mathrm{E}$ must be given at meals (Iuliano et al. 2001). To overcome these problems, new functional foods have been designed to enhance the bioavailability of antioxidant vitamins (Pons et al. 2002).

It is well known that oranges contain a high concentration of vitamin C (50 mg vitamin C/100 g) and that almonds contain a high concentration of vitamin E $(20 \mathrm{mg}$ vitamin $\mathrm{E} /$ $100 \mathrm{~g}$; Feinberg et al. 1995; Mataix et al. 2003; Moreiras et al. 2003). To assess the contribution of an isotonic orange and almond-based beverage (Pons et al. 2002) as a vehicle to increase the bioavailability of vitamin $\mathrm{E}$, female volunteers received a $250 \mathrm{mg} \alpha$-DL-tocopherol acetate capsule together with $500 \mathrm{ml}$ isotonic almond beverage ( $n$ 10) or $500 \mathrm{ml} \mathrm{min-}$ eral water $(n 9)$. There were no differences between groups 
in anthropometric characteristics (BMI: $\left.23 \cdot 1(\mathrm{SD} 1 \cdot 2) \mathrm{kg} / \mathrm{m}^{2}\right)$ or in daily dietary intake. Blood samples were taken at baseline and $4 \mathrm{~h}$ after the supplementation to determine vitamin E, glucose, total protein, uric acid, total and direct bilirubin and triacylglycerol plasma levels. Insulin serum levels were determined at baseline and also 1, 2 and $4 \mathrm{~h}$ after the supplementation. The subjects who had taken the vitamin E capsule with the orange and almond-based beverage showed higher plasma levels of vitamin $\mathrm{E}(+33 \%)$ and vitamin E:VLDL-cholesterol ratio $(+64 \%), 4 \mathrm{~h}$ after the supplementation, than those who had taken water (Fig. 1); both values being within the normal range. The orange and almond-based beverage was found to have no effect on blood metabolites. An increase in insulin levels was observed only $1 \mathrm{~h}$ after the orange and almond-based beverage was taken, probably due to its energy and nutrient content. A single dose of vitamin $\mathrm{E}$ was enough to increase plasma levels of this vitamin. Therefore, the orange and almondbased beverage used increased vitamin $\mathrm{E}$ bioavailability. It contained $203 \mathrm{~kJ} / 100 \mathrm{ml}, 1.9 \%$ lipid, $6.8 \%$ total sugar, $1.0 \%$ protein, $1.8 \mathrm{mg} \mathrm{Ca} / 100 \mathrm{ml}, 4.2 \mathrm{mg} \mathrm{Mg} / 100 \mathrm{ml}, 12.8 \mathrm{mg} \mathrm{Na} /$ $100 \mathrm{ml}, 33.7 \mathrm{mg} \mathrm{K} / 100 \mathrm{ml}, 69.7 \mu \mathrm{g} \mathrm{Fe} / 100 \mathrm{ml}$ and $44.5 \mu \mathrm{g}$ $\mathrm{Zn} / 100 \mathrm{ml}$, and only traces of vitamins $\mathrm{C}$ and $\mathrm{E}$. The orange and almond-based beverage can be then enriched with additional vitamins $\mathrm{C}$ and $\mathrm{E}$ to attain good antioxidant vitamin blood levels (Cases et al. 2005).

\section{Blood cells as biomarkers of vitamins $\mathbf{C}$ and $\mathbf{E}$}

Vitamin C concentration in plasma is tightly controlled by mediated tissue transport, absorption and excretion. Plasma vitamin $\mathrm{C}$ concentration of about $60-70 \mu \mathrm{M}$ has been used as indicative of good dietary intake. Immune blood cells, such as lymphocytes and neutrophils, contain 1-4 mM concentrations of vitamin $\mathrm{C}$ and saturate at vitamin $\mathrm{C}$ doses between 100 and $200 \mathrm{mg}$ daily. Lymphocytes are reported to be saturated at plasma concentrations of $>50 \mu \mathrm{M}$. Thus, cells are saturated before plasma. When plasma vitamin $\mathrm{C}$ approaches maximal concentration, additional vitamin $\mathrm{C}$ is lost in urine. Vitamin C doses higher than $200 \mathrm{mg}$ daily would not be necessary to avoid oxidative damage in non-risk groups in the population (Padayatty et al. 2003). Thus, the lymphocyte

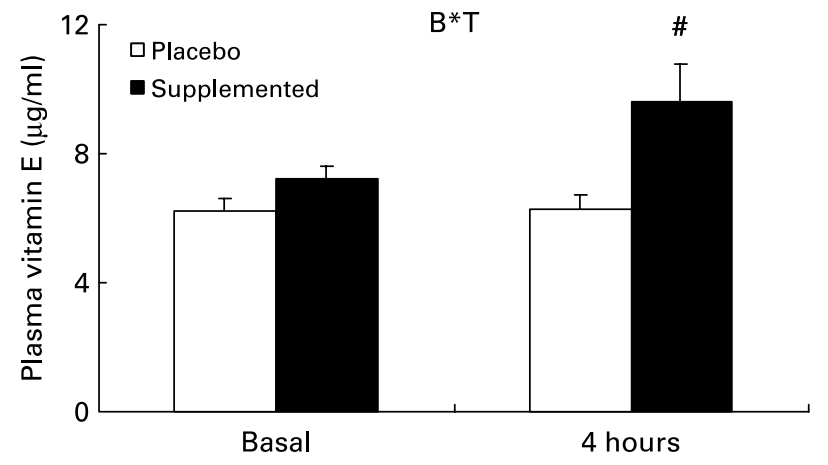

Fig. 1. Plasma vitamin E levels in almond beverage (supplemented) and water (placebo) groups. Capital letters indicate the significant effect of factor beverage $(B)$, time $(T)$ or the interaction $\left(B^{\star} T\right)$ by two-way ANOVA. (\#) Indicates significantly different values (Student's $t$ test for unpaired data, $P<0.05)$ between groups and time. or neutrophil vitamin $\mathrm{C}$ concentration is a good marker of the vitamin $\mathrm{C}$ status.

Plasma level of vitamin $\mathrm{E}$ is the most used biomarker to assess vitamin $\mathrm{E}$ status and is the one for which most data are available. A daily dietary intake of about $15-30 \mathrm{mg}$ $\alpha$-tocopherol is required to maintain optimal plasma levels. This amount of vitamin E could be obtained from dietary sources if a concerted effort was made to eat foods high in vitamin E. In contrast, the amounts of supplemental vitamin $\mathrm{E}$ suggested as protective from epidemiological studies are many times higher than those that could be obtained from the diet. The correlation between $\alpha$-tocopherol and blood lipids, especially cholesterol, is very strong. Consequently, it is recommended that plasma $\alpha$-tocopherol concentrations be lipid corrected. Plasma vitamin E is quickly redistributed between tissues, mainly in adipose tissue, and has been indicated not to reflect vitamin E status. For this reason, it has been pointed out that the adipose tissue vitamin E could be used as an useful measure of vitamin E status (Kayden et al. 1983).

During exercise, there is increased mitochondrial respiration, allowing for greater ROS production through the incomplete reduction of oxygen to water. In response to exercise-induced muscle damage, neutrophils and macrophages migrate to the site, infiltrate the muscle tissue, activate cytokines and produce additional ROS. Excess generation of ROS may overwhelm natural cellular antioxidant defences leading to lipid peroxidation and further contributing to muscle damage. Thus, there is an apparent paradox between the benefits of moderate and the damage of strenuous exercise. Sportsmen who practise exhaustive exercise present increased oxidative stress risk, and increased demand for antioxidant vitamins. The higher ROS production induced by exercise could use the vitamin $\mathrm{E}$ depots in tissues in order to counteract this ROS production. Then, exercise is a good model to establish the importance of plasma vitamin $\mathrm{E}$ to reflect the tissue status for this vitamin. In a previous work we demonstrated that the recommended daily intake of vitamin $\mathrm{E}$ is insufficient to avoid the oxidative stress induced by intense exercise (a mountain stage) in professional cyclists (Cases et al. 2003). Plasma vitamin E levels fall below baseline after intense exercise such as a mountain stage in cyclists (Aguiló et al. 2005).

The dose levels of antioxidants administered seems to be important to decrease the deleterious effects induced by exercise. Administration of $330 \mathrm{mg}$ vitamin E daily decreases oxidative stress markers after intensive aerobic training in cyclists (Rokitzki et al. 1994). Administration of lower daily doses of vitamin E (20 mg $\alpha$-tocopheryl succinate) and ascorbic acid $(120 \mathrm{mg})$ for 4 weeks to triathletes decreases muscle damage (Palazzetti et al. 2004).

In a previous study, we evaluated the effects of vitamin $\mathrm{C}$ diet supplementation on plasma and lymphocyte levels of this vitamin after repetitive episodes of hypoxia-reoxygenation induced by diving apnoea (Sureda et al. 2004). Seven volunteer male professional apnoea divers participated in this study. The sportsmen were divided randomly into two groups. One group was supplemented with vitamin C capsules $(1 \mathrm{~g} / \mathrm{d})$ for 7 days, and the other group took a placebo. This study was a double-blind crossover study. Ten days after the first diving apnoea session wash-out period, we repeated the procedure but changing the diet-supplemented 
capsules, i.e. the first group supplemented with vitamin C was now supplemented with placebo. The subjects practised diving in apnoea for about $4 \mathrm{~h}$ remained intermittently more than $1 \mathrm{~h}$ without breathing and under hypoxic conditions. After the supplementation, placebo and supplemented group had similar plasma and lymphocyte basal values of vitamin C. Plasma vitamin $C$ increased only in the supplemented group after diving. Also, the vitamin $\mathrm{C}$ concentration in lymphocytes increased after diving apnoea but the increase was significant only in the supplemented group.

In other work (Cases et al. 2005), we studied the combined effects of a 1-month supplementation with antioxidant vitamins $\mathrm{C}$ and $\mathrm{E}$ on exercise-induced oxidative stress. Fourteen male trained amateur runners (age: 34.5 (SD 3.6) years; BMI: $23 \cdot 1$ $(\mathrm{SD} 0.6) \mathrm{kg} / \mathrm{m}^{2}$ ) volunteered to take part in this study. They all trained for $7.5(\mathrm{SD} \mathrm{1.3)h}$ each week. The subjects took neither antioxidant dietary supplement nor any routine medication for 1 month prior to the study. Daily intake of antioxidant vitamins in the supplemented group was 60 (SD 1) $\mathrm{mg}$ for vitamin E and 277 (SD 30) $\mathrm{mg}$ for vitamin C, whereas the corresponding values in the placebo group were 14.8 (SD 1.2) $\mathrm{mg}$ and 162 (SD 29) $\mathrm{mg}$. We used antioxidant doses that can be provided by a diversified and well-balanced diet. After 1 month, subjects participated in a half-marathon race (21 km run). The athletes took a mean time of 91 (SE 10) min to finish the race. Basal plasma and lymphocyte levels of vitamin $\mathrm{C}$ and $\mathrm{E}$ were unchanged after supplementation. However, plasma vitamin C concentration increased $(+30 \%)$ after exercise only in the supplemented group and returned to basal values after $3 \mathrm{~h}$ recovery, whereas vitamin E remained at basal values. Lymphocytes in the supplemented group had increased $(+40 \%)$ vitamin $C$ content after exercise that remained high after the short recovery period. Lymphocyte vitamin $\mathrm{C}$ contents maintained basal levels in the placebo group. After the exercise (half-marathon), vitamin E levels in lymphocytes and neutrophils of the supplemented subjects were practically twice the levels before exercise and these levels remained high after recovery. The increase was higher in the supplemented group (about $130 \%$ ) than in the placebo (about $100 \%$ ). Neutrophils vitamin E contents of the placebo group were close to those in plasma. However, the contribution of neutrophils and lymphocytes to blood vitamin E contents is of low importance, because most of the blood vitamin E content came from plasma.

The higher antioxidant vitamin availability allows the lymphocytes to increase their antioxidant defences in order to avoid the deleterious effects of ROS induced by intense exercise. Immune blood cells accumulate vitamin $\mathrm{E}$ to prevent auto-oxidative processes, and therefore maintain their functionality. These results show that antioxidant vitamins exert a protective effect on oxidative stress on human cells, but also that intense exercise promotes mechanisms to accumulate antioxidant vitamins into cells sensitive to the effects of ROS.

\section{Conclusions}

Our findings suggest that the determination of antioxidant vitamin content in lymphocytes and neutrophils after exercise is a useful tool to assess the functional status of antioxidant vitamins in both individuals and populations, especially among sportsmen.

\section{Acknowledgements}

This work has been supported by the Spanish Ministry of Health (Programme of Promotion of Biomedical Research and Health Sciences, Project PI021593).

\section{References}

Aguiló A, Tauler P, Fuentespina E, Tur JA, Córdova A \& Pons A (2005) Antioxidant response to oxidative stress induced by exhaustive exercise. Physiol Behav 84, 1-7.

Aguiló A, Tauler P, Guix P, Villa G, Córdova A, Tur JA \& Pons A (2003) Effect of exercise intensity and training on antioxidants and cholesterol profile in cyclists. J Nutr Biochem 14, 319-325.

Cases N, Aguiló A, Tauler P, Sureda A, Llompart I, Pons A \& Tur JA (2005) Differential response of plasma and immune cell's vitamin E levels to physical activity and antioxidant vitamin supplementation. Eur J Clin Nutr, 59, 781-788.

Cases N, Sureda A, Tauler P, Aguiló A, Villa G, Córdova A, Pons A \& Tur JA (2003) Vitamin E recommended daily intake is not enough to avoid the oxidative stress induced by intense exercise. Proceedings of the Meeting 'Oxidants and Antioxidants in Biology', A Joint Meeting of the Oxygen Club of California, The University of Cádiz (Spain), and The Free Radicals Spanish Group. El Puerto de Santa María, Cádiz.

Feinberg M, Favier C \& Ireland-Ripert J (1995) Répertoire Géneral Des Aliments. París: Tec \& Doc Lavoisier.

Food and Nutrition Board, Institute of Medicine (2000) Dietary Reference Intakes for Vitamin C, Vitamin E, Selenium, and Carotenoids. Washington, DC: National Academy Press.

Hamilton IM, Gilmore WS, Benzie IF, Mulholland CW \& Strain JJ (2000) Interactions between vitamins $\mathrm{C}$ and $\mathrm{E}$ in human subjects. Br J Nutr 84, 261-267.

Horwitt MK (2001) Critique of the requirement for vitamin E. Am J Clin Nutr 73, 1003-1005.

Iuliano L, Micheletta F, Maranghi M, Frati G, Diczfalusy U \& Violi F (2001) Bioavailability of vitamin $\mathrm{E}$ as a function of food intake in healthy subjects: effects on plasma peroxide-scavenging activity and cholesterol-oxidation products. Arterioscler Thromb Vasc Biol 21, E34-E37.

Kayden HJ, Hatam LJ \& Traber MG (1983) The measurement of nanograms of tocopherol from needle aspiration biopsies of adipose tissue: normal and abetalipoproteinemic subjects. J Lipid Res 24, 652-656.

Leonard SW, Good CK, Gugger ET \& Traber MG (2004) Vitamin E bioavailability from fortified breakfast cereal is greater than that from encapsulated supplements. Am J Clin Nutr 79, 86-92.

Ji LL (1999) Antioxidants and oxidative stress in exercise. Proc Soc Exp Biol Med 222, 283-292.

Mataix J, Mañas M, Llopis J, Martínez de Victoria E, Juan J \& Obregón A (2003) Spanish Food Composition Tables (in Spanish), 4th ed. Granada: INTA, University of Granada.

Moreiras O, Carvajal A, Cabrera L \& Cuadrado C (2003) Food Composition Tables (in Spanish), 7th ed. Madrid: Piramide.

Morrisey PA \& Sheehy PJA (1999) Optimal nutrition: vitamin E. Proc Nutr Soc 58, 459-468.

Packer L \& Obermüller-Jevic UC (2002) Vitamin E in disease prevention and therapy: future perspectives. In The Antioxidant Vitamins $C$ and E, pp. 255-288 [L Packer, MG Traber, Kraemer and B Frei, editors]. Champaign, IL: AOCS Press.

Padayatty SJ, Katz A, Wang Y, et al. (2003) Vitamin C as an antioxidant: evaluation of its role in disease prevention. Am J Coll Nutr 22, 18-35. 
Palazzetti S, Rousseau AS, Richard MJ, Favier A \& Margaritis I (2004) Antioxidant supplementation preserves antioxidant response in physical training and low antioxidant intake. Br J Nutr 91, $91-100$.

Pons A, Tur JA, Tauler P, Aguiló A, Cases N \& Piña A (2002) Isotonic energy drink and procedure for obtaining it. PCT/IB02/02503.

Rokitzki L, Logemann E, Huber G, Keck E \& Keul J (1994) Alphatocopherol supplementation in racing cyclist during extreme endurance training. Int J Sport Nutr 4, 253-264.
Sureda A, Batle JM, Tauler P, Aguiló A, Cases N, Tur JA \& Pons A (2004) Hypoxia/reoxygenation and vitamin C intake influence NO synthesis and antioxidant defenses of neutrophils. Free Radic Biol Med 37, 1744-1755.

Traber MG (2001) Vitamin E: too much or not enough ? Am J Clin Nutr 73, 997-998.

Traber MG, Winklhofer-Roob BM, Roob JM, Khoschsorur G, Aigner R \& Cross C (2001) Vitamin E kinetics in smokers and nonsmokers. Free Radic Biol Med 31, 1368-1374. 